\title{
Preparation and Properties of Core-Shell Structure/Ni60 Coating
}

\author{
Wang Xinsheng, ${ }^{1}$ Yanpei Liu, ${ }^{2}$ Junjian Hou, ${ }^{1}$ Wenbin He, ${ }^{1}$ Kun Liu, ${ }^{1}$ and She Zhaobin ${ }^{3}$ \\ ${ }^{1}$ Hennan Key Laboratory of Intelligent Manufacturing of Mechanical Equipment, \\ Henan Engineering Research Center of New Energy Vehicle Light Weight Design and Manufacturing, \\ Zhengzhou University of Light Industry, Zhengzhou 430002, China \\ ${ }^{2}$ Zhengzhou University of Light Industry, Zhengzhou 430002, China \\ ${ }^{3}$ Measurement and Physical and Chemical Analysis Center, Xi'an North Qinghua Electromechanical Co., Ltd., Xi'an City, China
}

Correspondence should be addressed to Yanpei Liu; 2017041@zzuli.edu.cn

Received 9 August 2021; Revised 9 October 2021; Accepted 12 October 2021; Published 9 November 2021

Academic Editor: Guo-Qing Zhang

Copyright (๑) 2021 Wang Xinsheng et al. This is an open access article distributed under the Creative Commons Attribution License, which permits unrestricted use, distribution, and reproduction in any medium, provided the original work is properly cited.

\begin{abstract}
As the most important element in improving the service life of a mechanical system, surface coating materials are of key importance in the development of high-end equipment. To improve the comprehensive properties of the surface coating, the common core-shell structure/Ni60 coating was prepared on the surface of \#45 steel by supersonic plasma spraying. The results show that the Ni60 has no layer structure, pores, cracks, and other defects on the surface of the coating. The nanohardness of the $\mathrm{NNA}\left(\mathrm{Ni60} / \mathrm{Ni}(\mathrm{Al})\right.$ mixture powder), $\mathrm{NNM}\left(\mathrm{Ni} 60 / \mathrm{Ni}\left(\mathrm{MoS}_{2}\right)\right.$ mixture powder), and $\mathrm{NNC}(\mathrm{Ni} 6 / \mathrm{Ni}(\mathrm{C})$ mixture powder) coatings is $6815 \mu \mathrm{N}, 5750 \mu \mathrm{N}$, and $2000 \mu \mathrm{N}$. The results show that the wear resistance of the NNA coating is better. In the friction and wear test, the NNA coating mainly shows adhesive wear and abrasive wear, while the NNM and NNC coatings mainly show abrasive wear.
\end{abstract}

\section{Introduction}

Supersonic plasma technology uses a plasma arc as the heat source to heat the working gas to form a hightemperature and high-speed plasma jet; the plasma spray coatings present better corrosion and wear resistance compared with the flame and arc spray coatings [1]. This is used to heat, accelerate, and form a molten particle flow that accelerates (or accelerate after atomization) to form high-speed droplets and impacts the substrate before being flattened into a coating. Rapid cooling solidification deposition is a material forming method that forms a coating on the surface of the substrate; however, this method only results in a mechanical bond between the substrate and the coating, resulting in limited bonding strength $[2,3]$. In the past, supersonic spraying was realized using a single component powder as the raw material, making it difficult to realize particular requirements $[4,5]$. Therefore, studies on composite powders have become more relevant. Conventional composite powders are mixed mechanically; however, it is difficult to achieve uniform mixing and to avoid segregation of the components, which could significantly affect the performance of the coating [6]. The core-shell composite powder is a new type of composite material developed in recent years and is composed of the core particles and the coating layer. On the one hand, the different phases in the core-shell structure composite powder can achieve a uniform degree of mixing of the components at the particle level, which overcomes the disadvantages of conventional mixed composite powders, such as the composition segregation and uneven mixing. On the other hand, it has the favorable properties of both shell and core materials, the core-shell structure can prepare the coating with good bonding, no obvious cracks and pores, uniform distribution, and wear-resistant performance, and the bonding force between the coating and the substrate will improve the quality and service time of the coating, which can endow the powder with a favorable property profile [7-10]. In this article, Ni-based powder for supersonic 
plasma spraying is used as the main raw material, and the Co-composite process for metallurgical bonding in the transition layer is realized by adding core-shell structure materials [11]. The core-shell materials are $\mathrm{Ni}(\mathrm{Al}), \mathrm{Ni}$ (MoS2), and $\mathrm{Ni}(\mathrm{C})$. The comparative verification of the preparation process and performance of the coating is explored.

\section{Experimental Method}

2.1. Raw Materials. In this experiment, the raw material is self-soluble Ni60 powder. Because the powder has excellent comprehensive properties, especially corrosion resistance, wear resistance, and strong antioxidation ability, it is suitable for supersonic plasma spraying and thermal spraying. The chemical composition of the Ni60 powder (in wt\%) is $\mathrm{Cr}$ 14.0-16.0, Si 3.5-5.0, B 2.5-3.5, C 0.6-1.0, Fe $\leq 5$, and balanced $\mathrm{Ni}$. The $\mathrm{Ni}(\mathrm{Al})$ core-shell composite powder has a "self-adhesive" effect, in which $\mathrm{Ni}: \mathrm{Al}=4: 1$ (wt\%). In the process of thermal spraying, $\mathrm{Ni}$ and $\mathrm{Al}$ react to form intermetallic compounds and release a lot of heat. This reaction process can last until the powder collides with the surface of the substrate, which could improve the bonding strength between the coating and the substrate. At the same time, there is a "self-adhesive" effect between the coating and the Ni60 powder, which realizes the metallurgical bonding of the coating and enhances the wear resistance of the coating $[12,13]$. The results show that $\mathrm{Ni}(\mathrm{C})$ core-shell powder has good bonding, uniform distribution of $\mathrm{C}$, and wear resistance, in which $\mathrm{Ni}: \mathrm{C}=4: 1$ (wt $\%)$. The $\mathrm{Ni}(\mathrm{MoS} 2)$ shell core composite powder, which has a composition of $\mathrm{Ni}$ : MoS2 $=4: 1(\mathrm{wt} \%)$, is often used to prepare self-lubricating coatings. The MoS2 can wet and solidify the lubricating material, which improve the adhesion, heat resistance, and corrosion and wear resistance of the coating [14].

In the spraying process, the hard phase particles rebound less due to the coating effect of the bonding phase. High-quality coatings can be prepared easily on the substrate. The diameter of the sprayed powder purchased from Shanghai Haotian Metal Powder Co., Ltd is approximately $20-50 \mu \mathrm{m}$, and the purity is $99.5 \%$. These three kinds of core-shell structure powders were, respectively, added to Ni60 powder at a proportion of $15 \%(\mathrm{wt})$. The coating prepared using $\mathrm{Ni60} / \mathrm{Ni}(\mathrm{Al})$ powder was designated as NNA: the one using Ni60/Ni (MoS2) powder was named $\mathrm{NNM}$ and the one using $\mathrm{Ni60/Ni}(\mathrm{C})$ powder was named NNC. Figure 1(a) shows the core-shell structure, and Figure 1(b) shows the micromorphology of the core-shell structure.

2.2. Preparation Coating. HLD-8000 supersonic plasma spraying equipment produced by Zhengzhou Lijia Thermal Spraying Machinery Co., Ltd. was used to prepare the composite coating. The matrix material was a round $45 \#$ steel plate $(\Phi 20 \mathrm{~mm} \times 10 \mathrm{~mm})$. Before spraying, the preprocess steps included sandblasting, roughening, acetone cleaning, acidification, and alcohol cleaning. Before preparation, the powders were mixed in a ball mill having a
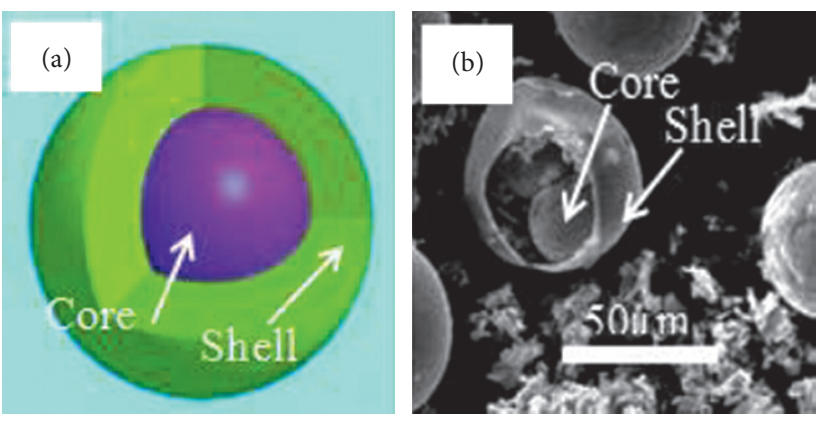

FIgURE 1: Core-shell structure diagram: (a) schematic diagram of core-shell structure; (b) microstructure of core-shell structure.

milling rate of $150 \mathrm{r} / \mathrm{min}$; the ball-material ratio was $3: 1$, and the ball milling time was $4 \mathrm{H}$, and the material of the ball is GCr15 steel. The spraying process parameters after preheating the substrate are as follows: spraying voltage $110 \mathrm{~V}$, spraying current $320 \mathrm{~A}$, spray gun distance $120 \mathrm{~mm}$, powder feeding voltage $11 \mathrm{~V}$, Ar gas $3.5 \mathrm{~m}^{3} / \mathrm{h}$, secondary gas $\mathrm{H} 2$ $0.25 \mathrm{~m}^{3} / \mathrm{h}$, and spraying layer thickness $\sim 0.5 \mathrm{~mm}$. After spraying, the sand is slowly cooled to room temperature. The schematic of the coating preparation process is shown in Figure 2.

2.3. Characterization Methods. The phase structure of the coating was analyzed using Shimadzu $7000 \mathrm{X}$-ray diffraction equipment (XRD, Rigaku Compact, Tokyo, Japan). The surface and cross section morphologies of the coating were observed by using a Merlin compact scanning electron microscope (SEM, Thuringia, Germany).

The nanohardness of the coating surface was tested by using Hysitron Ti 950 nanoindenter. The pressure head was loaded with $5 \mathrm{~N}$, and the indentation depth was $150 \mathrm{~nm}$.

An MFT-R4000 reciprocating friction and wear testing machine was used to test the friction and wear of the coating (Zhongke Kaihua Technology Co., Ltd., Gansu); the coating of the wear test was the polishing coating of the $s$ surface ample. The disc ball contact mode was adopted between the coating and the counter wear parts. The ball bearing steel (GCr13) with a hardness of $600 \mathrm{Hv}$ and diameter of $3 \mathrm{~mm}$ was selected for the reciprocating test $(\mathrm{L}=8 \mathrm{~mm})$. The test was carried out in air at room temperature for $30 \mathrm{~min}$, and the selected loads were $10 \mathrm{~N}$. The micro XAM-800 3D profilometer was used to characterize the worn surface, and the maximum wear depth and wear scar distance were measured.

\section{Experimental Results and Discussion}

3.1. Microstructure Analysis of Coatings. Figure 3 shows the micromorphology of the three kinds of coatings. Considering the surface, there are micropores on all three kinds of coatings, and the pores in Figure 3 (a) are fewer as calculated by the Gibbs free energy formula [15]:

$$
\Delta G=\Delta H-T \Delta S,
$$




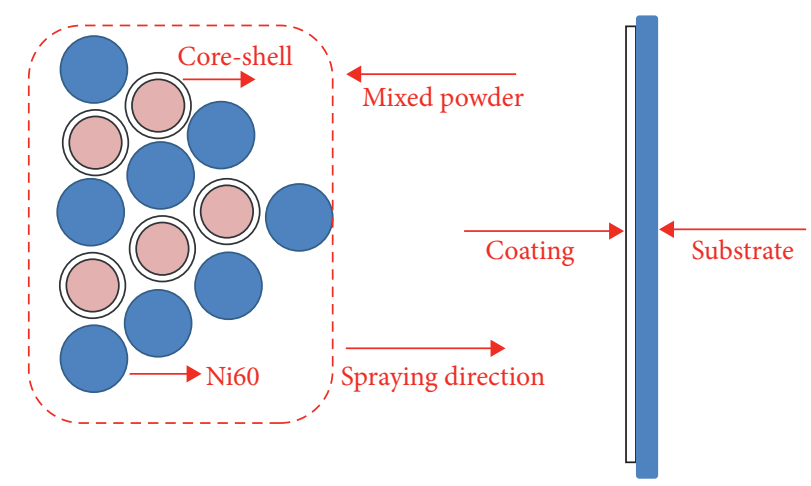

FIgURE 2: Schematic diagram of coating preparation process.
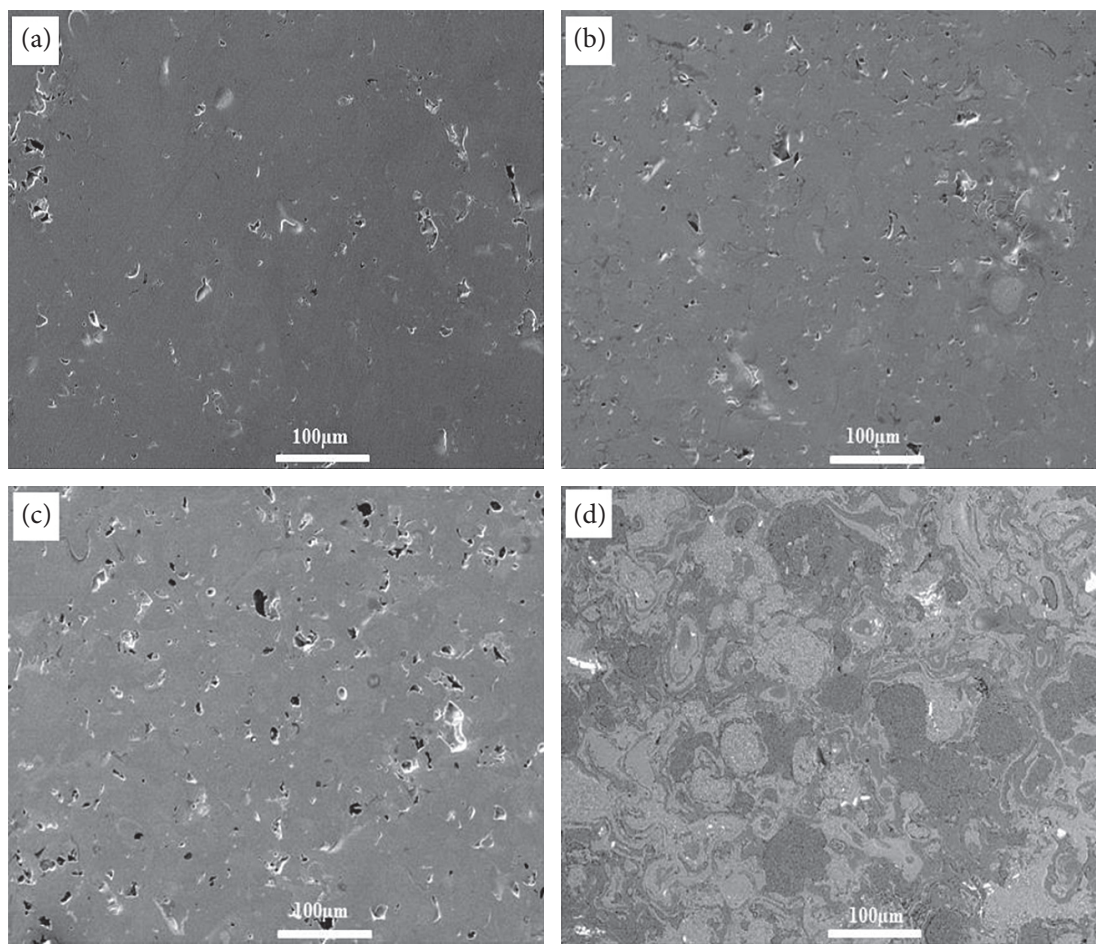

FIGURE 3: Microstructure of four kinds of coating materials: (a) NNA; (b) NNM; (c) NNC; (d) Ni60.

where $\Delta \mathrm{H}$ is the enthalpy, $\Delta \mathrm{S}$ is the entropy, and $\mathrm{T}$ is the temperature.

$$
\begin{gathered}
3 N i+A 1=N i 3 A I+Q \\
N i+A 1=N i A 1+Q \\
A 1+O 2=A 203+Q
\end{gathered}
$$

When the spraying heat source temperature is $660-680^{\circ} \mathrm{C}$, an exothermic reaction occurs between the components, and the $\mathrm{Ni3Al}, \mathrm{NiAl}$, and $\mathrm{Al} 2 \mathrm{O} 3$ intermetallic compounds are formed. The matrix and spray particles are heated sufficiently by the exothermic reaction, which facilitates the micrometallurgical bonding between the molten spray particles and the thin layer on the surface of the matrix, generates a strong bonding force, and produces a "self-adhesive" effect [16]. Porosity software Image $2 \mathrm{x}$ was used to test the porosity of the four coatings, respectively, (a) $\mathrm{NNA}(4.3 \%)$, (b) $\mathrm{NNM}(5.7 \%$ ), (c) $\mathrm{NNC}(7.2 \%)$, and (d) $\mathrm{Ni60}(2.4 \%)$. The increase in porosity in Figure 3(b) is due to the existence of some pores in the gap between the core and shell of Ni (MoS2) with the core-shell structure. In Figure 3(c), the porosity of the coating surface increases, which is may be due to the metallurgical reaction of $\mathrm{Ni}(\mathrm{C})$ produced by the core-shell during the spraying process. A part of $\mathrm{C}$ exists in the coating as a free substance, and a part of $\mathrm{C}$ reacts, which causes the $\mathrm{CO}$ to escape from the coating in the form of a gas and increases the porosity. However, the above three coating structures form a metallurgical bond, and there is no layered structure with mechanical bonding in the Ni60 coating, as shown in Figure 3(d).

3.2. Analysis of Coating Phase Structure. The XRD diagram in Figure 4, which depicts all three coating types, shows only the $\mathrm{Ni}$ diffraction peak, and there are no diffraction peaks 


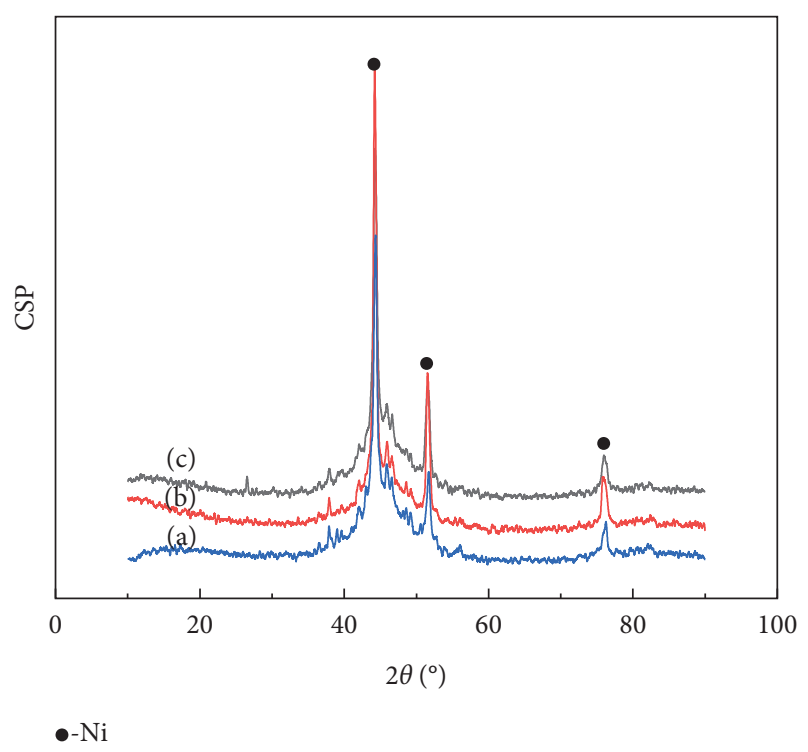

Figure 4: Phase structure of three coating materials: (a) NNA; (b) NNM; (c) NNC.

corresponding to the intermetallic compound. Hence, it can be deduced that the core-shell structure of powder in the supersonic plasma jet has not undergone a strong exothermic reaction. This may be because (1) the content of other elements in the Ni-based powder is very low, especially in the core-shell structure of the powder. As core-shell structure, Al, MoS2, and C are not firmly bonded to the Ni shell, and some of them have fallen off [17-19], as shown in Figure 1(b). When the mixed powder is sent to the supersonic plasma jet, these cored-shell structure particles are easily impacted by the rigid jet and cannot be melted uniformly. (2) The particle size and specific gravity of $\mathrm{Al}$ and $\mathrm{C}$ in the $\mathrm{Ni}(\mathrm{Al})$ and $\mathrm{Ni}(\mathrm{C})$ coreshell structure powders differ greatly from that of $\mathrm{Ni}$, and the acceleration of $\mathrm{Al}$ and $\mathrm{C}$ powders after peeling is considerably high. It is difficult for the powders to melt synchronically and undergo exothermic reaction [20].

3.3. Hardness Analysis of Coating. Figure 5 shows the indentation load displacement curves of the three coating materials. All three materials have experienced loading and unloading stages during the test process. With the increase in indentation depth, the loading curve changes smoothly, and there is no "step" curve, which also indicates that the internal structure of the coating is relatively uniform. When the indentation depth reaches $137 \mathrm{~nm}$, the loading force of the three coating materials reaches the maximum value, and the nanohardness in Figure 5(a) reaches the maximum value of $6815 \mu \mathrm{N}$. This is also due to the "self adhesion" effect of $\mathrm{Al}$ particles in the $\mathrm{Ni}(\mathrm{Al})$ core-shell structure materials, which forms intermetallic compounds and encourages mutual diffusion between particles, and the bonding strength of the coating is enhanced, which is also consistent with the change of surface pores in the micromorphology in Figure 3. The nanohardness in Figure 5 (b) is $5750 \mu \mathrm{N}$. This is because the addition of $\mathrm{Ni}(\mathrm{MoS} 2)$ core-shell structure materials does not form intermetallic compounds, and MoS2 particles influence

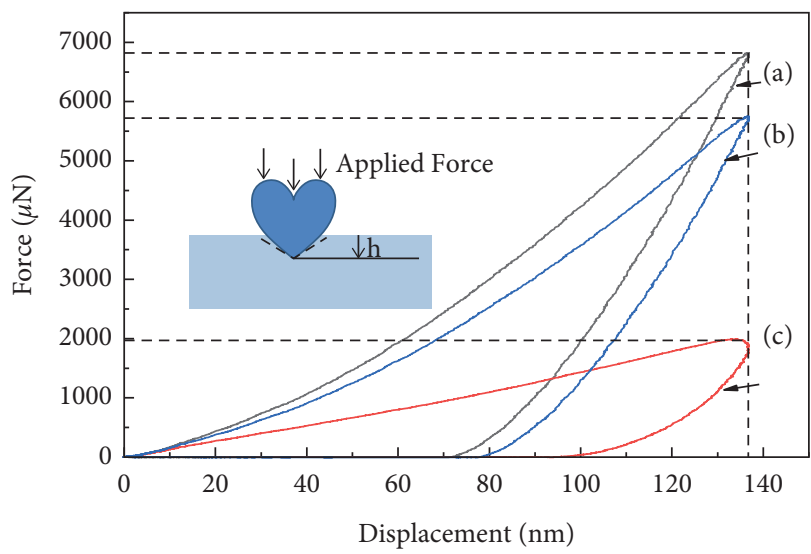

FIgURE 5: Nanohardness of three coating materials: (a) NNA, (b) NNM, and (c) NNC.

dispersion strengthening and increase the bonding strength of the coating. Figure 5(c) shows a nanohardness of $2000 \mu \mathrm{N}$. Compared with the other two kinds of coatings, the nanohardness of $\mathrm{Ni}(\mathrm{C})$ core-shell structure material is greatly reduced, which is due to the chemical reaction between $\mathrm{C}$ particles and oxygen at high temperatures, resulting in the release of gases that increase the porosity of the coating and reduce the bonding strength of the coating, which is also consistent with the micropore morphology in Figure 3(c).

3.4. Analysis of Wear Performance of Coatings. The friction and wear properties can reflect the bonding strength of the coating. Figure 6 shows the relationship between the friction coefficient and sliding time of the three coating materials. Using the reciprocating friction of the stainless steel ball at the coating interface, it can be seen from the curve in Figure 6 that in the initial stage $(0-1 \mathrm{~min})$, the friction coefficient of the three coating materials increased rapidly and then decreased. The reason is that the core-shell structure materials are added to the three coating materials. At the initial stage, a part of the Ni shell structure first participates in the wear. After the friction failure of the Ni shell surface, the cores of the three core-shell structures, namely, Al, MoS2, and C, begin to participate in the friction. These three core-shell structure materials react with the Ni60 powder, and the friction coefficient also changes. It can be seen from Figure 6 that the friction coefficient of Figure 6(a) is the lowest at approximately 0.4 . This is because $\mathrm{Al}$ particles participate in the reaction during the spraying process, with the formation of $\mathrm{Ni} 3 \mathrm{Al}, \mathrm{NiAl}$, and $\mathrm{A} 2 \mathrm{O} 3$ intermetallic compounds, resulting in an increase in bonding strength and a decrease in friction coefficient. The friction coefficient of Figure 6(b) is approximately 0.7 as the MoS2 core structure has certain lubricating properties, but the additional quantity is limited, and there is no intermetallic compound or hard phase in the coating. The friction coefficient in Figure 6(c) is 1.1, which is the worst among the three coating materials. This is because the graphite is coated with nickel at the initial stage. Under the load, the nickel shell wears away, the wear surface becomes rough, and the friction coefficient increases rapidly. With the continuous appearance of $\mathrm{C}$ 


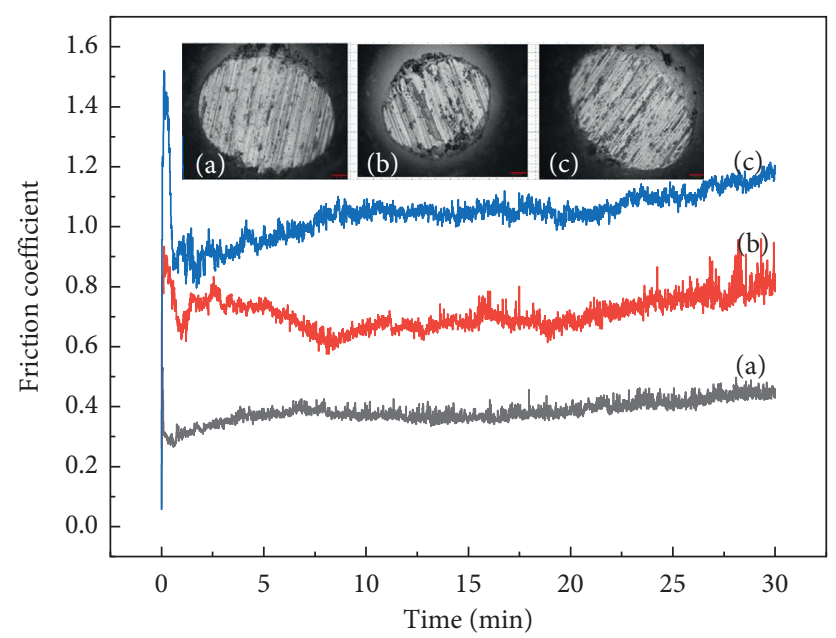

Figure 6: Friction coefficient curves of three coatings: (a) NNA; (b) NNM; (c) NNC.
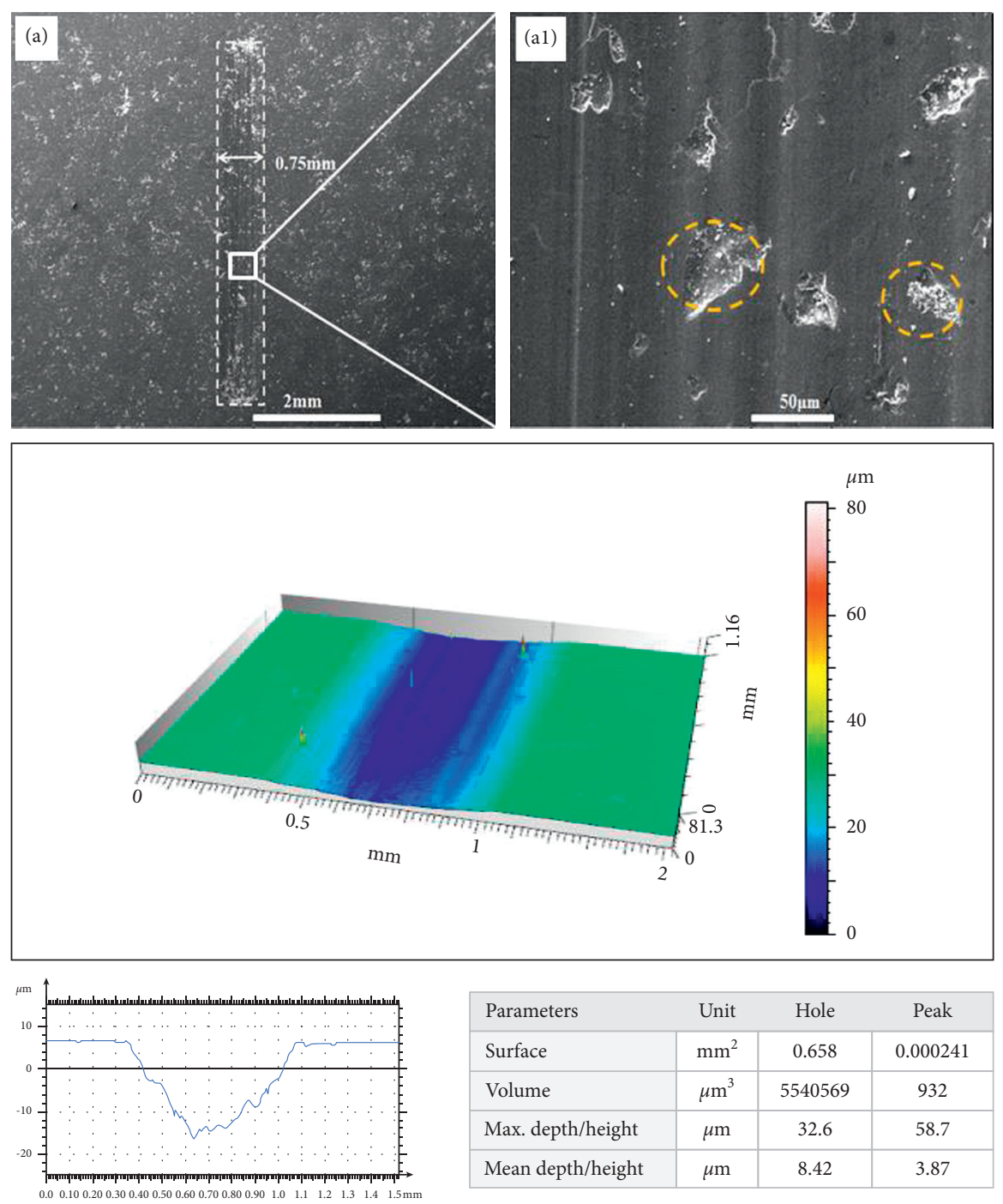

\begin{tabular}{|l|c|c|c|}
\hline Parameters & \multicolumn{1}{c}{ Unit } & Hole & Peak \\
\hline Surface & $\mathrm{mm}^{2}$ & 0.658 & 0.000241 \\
\hline Volume & $\mu \mathrm{m}^{3}$ & 5540569 & 932 \\
\hline Max. depth/height & $\mu \mathrm{m}$ & 32.6 & 58.7 \\
\hline Mean depth/height & $\mu \mathrm{m}$ & 8.42 & 3.87 \\
\hline
\end{tabular}

(a)

Figure 7: Continued. 

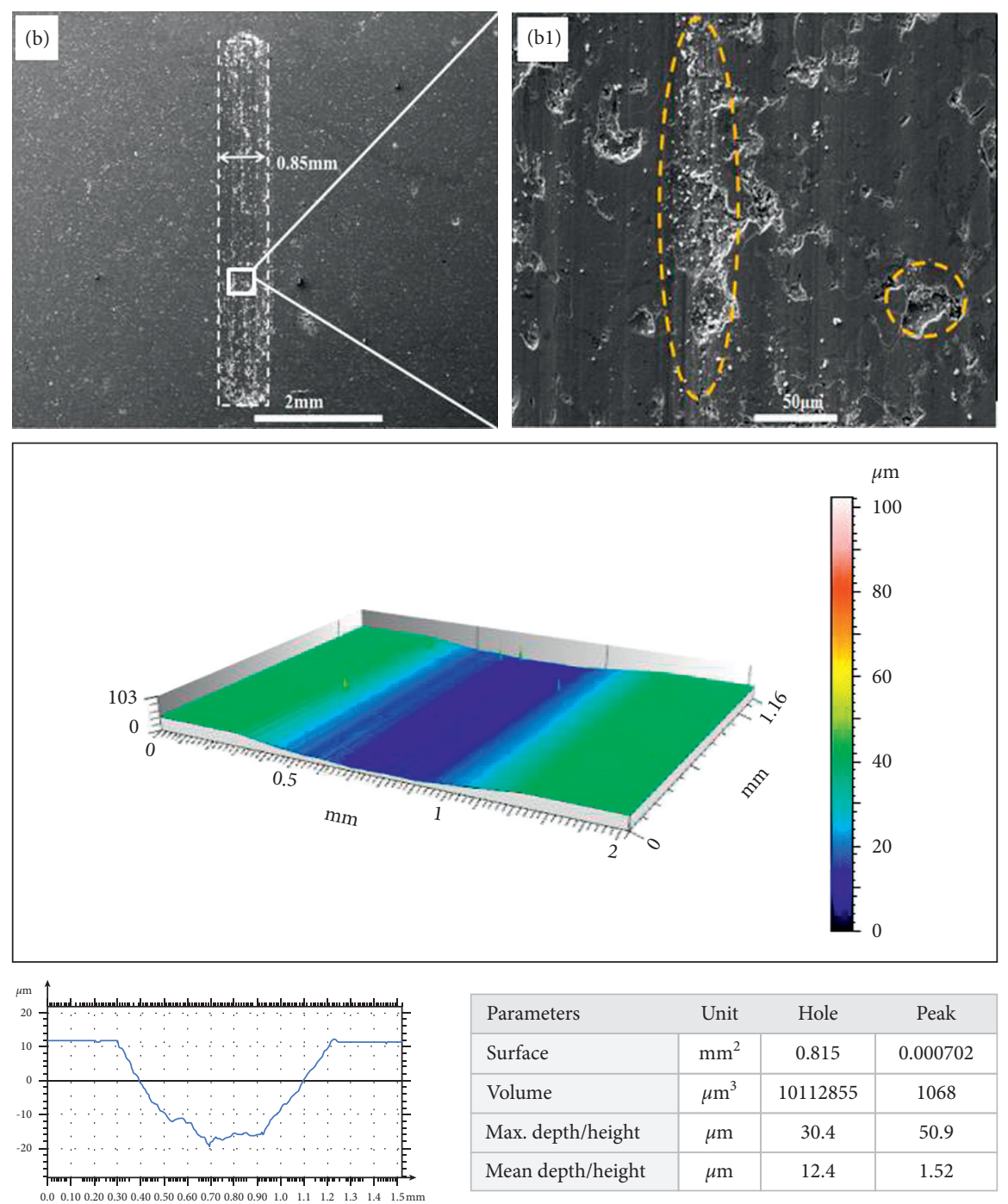

\begin{tabular}{|l|c|c|c|}
\hline Parameters & \multicolumn{1}{c}{ Unit } & Hole & Peak \\
\hline Surface & $\mathrm{mm}^{2}$ & 0.815 & 0.000702 \\
\hline Volume & $\mu \mathrm{m}^{3}$ & 10112855 & 1068 \\
\hline Max. depth/height & $\mu \mathrm{m}$ & 30.4 & 50.9 \\
\hline Mean depth/height & $\mu \mathrm{m}$ & 12.4 & 1.52 \\
\hline
\end{tabular}

(b)

Figure 7: Continued. 

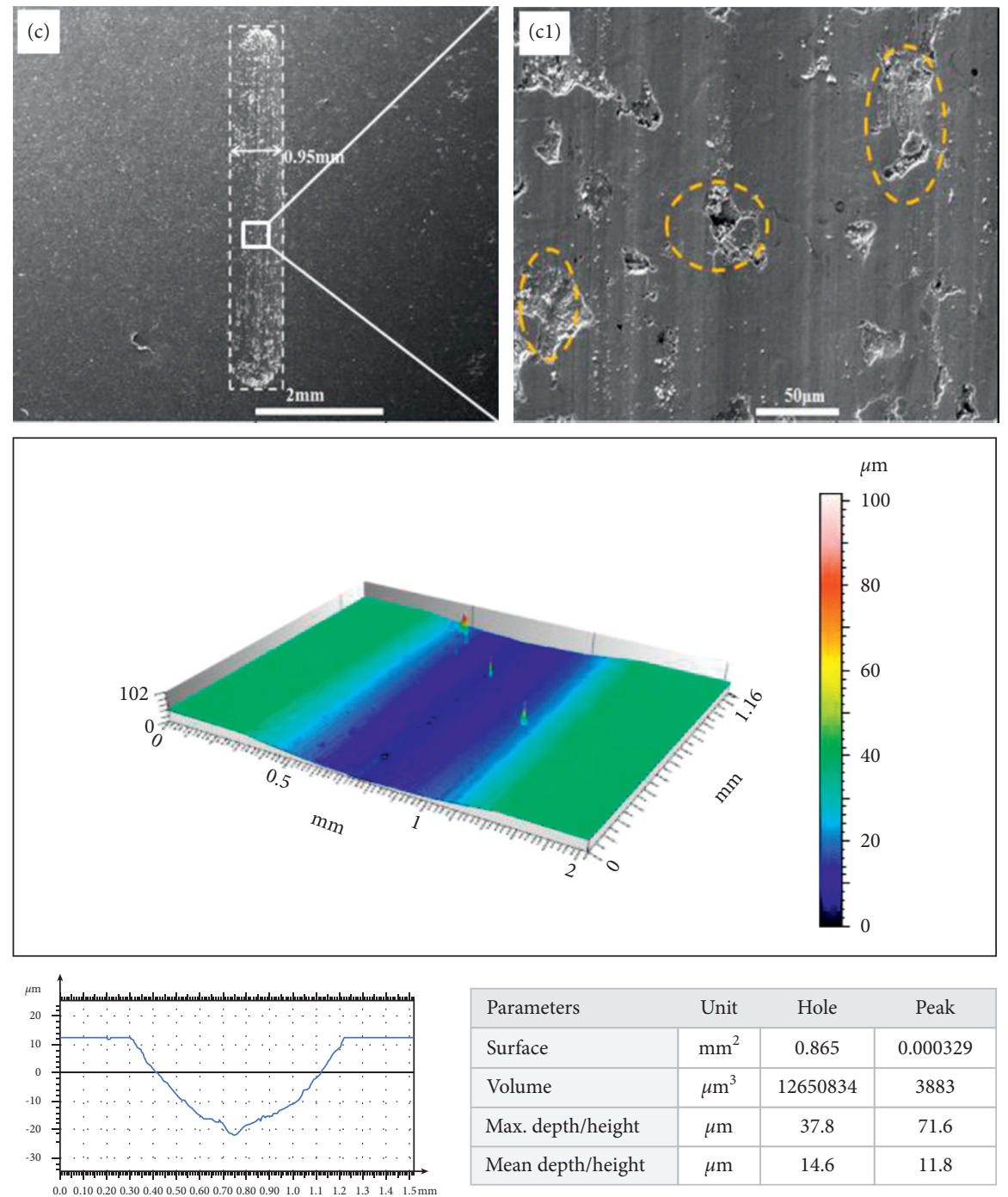

\begin{tabular}{|l|c|c|c|}
\hline Parameters & \multicolumn{1}{r}{ Unit } & Hole & Peak \\
\hline Surface & $\mathrm{mm}^{2}$ & 0.865 & 0.000329 \\
\hline Volume & $\mu \mathrm{m}^{3}$ & 12650834 & 3883 \\
\hline Max. depth/height & $\mu \mathrm{m}$ & 37.8 & 71.6 \\
\hline Mean depth/height & $\mu \mathrm{m}$ & 14.6 & 11.8 \\
\hline
\end{tabular}

(c)

Figure 7: Wear morphology and test values of three kinds of coating materials: (a) NNA; (b) NNM; (c) NNC.

particles, the lubrication effect of graphite stops the increase in the wear coefficient but gradually flattens and stabilizes at approximately 1.1 .

The micromorphology of the coating surface after friction was characterized. Figure 7 shows the worn morphology of the three coatings, and Figure 7(a) shows the worn morphology of NNA. The wear trace width is $0.75 \mathrm{~mm}$, and the maximum wear depth is $32.6 \mu \mathrm{m}$. Figure 7 (a) 1 shows that the main wear mechanism is that the GCr15 ball applies load in the form of normal stress and adheres to $\mathrm{Ni}$ and $\mathrm{Al}$ on the surface of the matrix. When there is relative sliding, the surface of the matrix is damaged and peels off continuously, resulting in furrows and pits. When the adhesive point is in the pit, furrowing will also occur along the pit, and the wear mechanism is adhesive wear. With the increase in friction time, the abrasive particles produced on the surface undergo constant rubbing, which makes the wear surface of the substrate susceptible to a slight spalling phenomenon that is manifested as the abrasive wear mechanism. Figure 7(b) shows the morphology of NNM coating after wear. The wear width increases to $0.85 \mathrm{~mm}$, and the maximum wear depth decreases to $30.4 \mu \mathrm{m}$. It can also be seen from Figure 7 (b1) that large areas of spalling appear on the surface of the coating. This is because nickel, as a hard phase, can bear a certain load after being stressed [21]. MoS2, as a dispersed phase in the coating, has a low bonding strength with $\mathrm{Ni}$, resulting in particle spalling in the friction process, which is manifested as abrasive wear mechanism. Figure 7(c) shows the worn morphology of the NNC coating. The maximum width of wear trace is $0.95 \mathrm{~mm}$, and the maximum wear depth is $37.8 \mu \mathrm{m}$. This is because $\mathrm{C}$ in the coating undergoes reactions, and pores also appear in the coating. However, due to the increase in compressive stress and shear stress, cracks begin to appear on the wear surface, and a small number of exfoliation pits appear, as shown in Figure 7(c1). This is because the hard phase $\mathrm{Ni}$ peeled out during wear is repeatedly rubbed and rolled under high stress, which results in the plastic deformation of the wear surface. With the repeated cutting action of abrasive particles, the furrow deepens, and 
subsequently, cracks are generated. The cracks continue to expand until slight spalling occurs. The wear mechanism of these two processes is mainly abrasive in nature.

\section{Conclusion}

(1) The nickel-based core-shell composite coating was prepared by the supersonic plasma method. The coating has no obvious defects such as cracks and pores, and the coating structure is metallurgically bonded.

(2) $\mathrm{Al}, \mathrm{MoS} 2$, and $\mathrm{C}$ phases do not appear in the phase structure of NNA, NNM, and NNC coatings. The nanohardness of the three coatings is $6815 \mu \mathrm{N}$, $5750 \mu \mathrm{N}$, and $2000 \mu \mathrm{N}$. Meanwhile, the friction coefficients are 0.4, 0.7, and 1.1, respectively, and the wear resistance of the NNA coating is better.

(3) Under a load of $10 \mathrm{~N}$ and reciprocating friction process, the NNA coating mainly shows adhesive wear and abrasive wear, while NNM and NNC coating mainly shows abrasive wear [22].

\section{Data Availability}

(1) The nickel-based core-shell composite coating was prepared by the supersonic plasma method. The coating has no obvious defects such as cracks and pores, and the coating structure is metallurgically bonded. (2) Al, MoS2, and C phases do not appear in the phase structure of NNA, NNM, and NNC coatings. The nanohardness of the three coatings is $6815 \mu \mathrm{N}, 5750 \mu \mathrm{N}$, and $2000 \mu \mathrm{N}$. Meanwhile, the friction coefficients are 0.4, 0.7, and 1.1, respectively, and the wear resistance of the NNA coating is better. (3) Under a load of $10 \mathrm{~N}$ and reciprocating friction process, the NNA coating mainly shows adhesive wear and abrasive wear, while NNM and NNC coating mainly shows abrasive wear.

\section{Conflicts of Interest}

The authors declare that they have no conflicts of interest.

\section{Acknowledgments}

This work was financially supported by the National Science Foundation of China (Nos. 61802353 and U2004169), Natural Science Foundation of Henan Province (No. 202300410505), Foundation of Key Laboratory of National Defense Science and Technology (No. 6142005200302), Training Program for Young Backbone Teachers in Colleges and Universities of Henan Province (No. 2019GGJS130), and Key Scientific and Technological Project of Henan Province (202102210290).

\section{References}

[1] T.-C. Chen, C.-C. Chou, T.-Y. Yung, R.-F. Cai, J.-Y. Huang, and Y.-C. Yang, "A comparative study on the tribological behavior of various thermally sprayed Inconel 625 coatings in a saline solution and deionized water," Surface and Coatings Technology, vol. 385, no. 15, pp. 125442-125453, 2020.
[2] X. Wang, Z. Xing, Y. Liu, J. Hou, and K. Liu, "Composite ceramic-Ni60 coating fabricated via supersonic plasma spraying," Chinese Journal of Physics, vol. 61, pp. 72-79, 2019.

[3] Z. Xing, H. Wang, L. Zhu, X. Zhou, and Y. Huang, "Properties of the $\mathrm{BaTiO} 3$ coating prepared by supersonic plasma spraying," Journal of Alloys and Compounds, vol. 582, pp. 246-252, 2014.

[4] F. Y. Shu, S. Liu, H. Y. Zhao et al., "Structure and hightemperature property of amorphous composite coating synthesized by laser cladding $\mathrm{FeCrCoNiSiB}$ high-entropy alloy powder," Journal of Alloys and Compounds, vol. 731, pp. 662-666, 2018.

[5] M. Wang, Y. Lu, G. Zhang et al., "A novel high-entropy alloy composite coating with core-shell structures prepared by plasma cladding," Vacuum, vol. 184, pp. 109905-109917, 2021.

[6] R. F. Gibson, "A review of recent research on mechanics of multifunctional composite materials and structures," Composite Structures, vol. 92, no. 12, pp. 2793-2810, 2010.

[7] Z. Zeng, S. Kuroda, and H. Era, "Comparison of oxidation behavior of $\mathrm{Ni}-20 \mathrm{Cr}$ alloy and Ni-base self-fluxing alloy during air plasma spraying," Surface and Coatings Technology, vol. 204, no. 1-2, pp. 69-77, 2009.

[8] L. L. Xiong, H. Z. Zheng, P. Yu, G. F. Li, Z. Chen, and B. Zhang, "Laser-clad YSZ@Ni (core-shell nanoparticle) composites coatings," Ceramics International, vol. 10, no. 41, pp. 13850-13854, 2015.

[9] T. Peat, A. Galloway, A. Toumpis, D. Harvey, and W.-H. Yang, "Performance evaluation of HVOF deposited cermet coatings under dry and slurry erosion," Surface and Coatings Technology, vol. 300, pp. 118-127, 2016.

[10] E. Sadeghimeresht, N. Markocsan, and P. Nylén, "Microstructural characteristics and corrosion behavior of HVAFand HVOF-sprayed Fe-based coatings," Surface and Coatings Technology, vol. 318, pp. 365-373, 2017.

[11] J.-J. Tian, X.-T. Luo, J. Wang, and C.-J. Li, "Mechanical performance of plasma-sprayed bulk-like NiCrMo coating with a novel shell-core-structured NiCr-Mo particle," Surface and Coatings Technology, vol. 353, pp. 179-189, 2018.

[12] X. Zhao, S. Yuan, Z. Jin et al., "Fabrication of composite coatings with core-shell nanofibers and their mechanical properties, anticorrosive performance, and mechanism in seawater," Progress in Organic Coatings, vol. 149, pp. 105893-105907, 2020.

[13] T. L. To, K. H. Dinh, M. C. Hoang et al., "Structure and magnetic properties of magnetic iron oxide/zinc oxide core/ shell nanocomposites: effect of $\mathrm{ZnO}$ coating," Materials Today Communications, vol. 26, pp. 101733-101741, 2021.

[14] J.-J. Tian, S.-W. Yao, X.-T. Luo, C.-X. Li, and C.-J. Li, “An effective approach for creating metallurgical self-bonding in plasma-spraying of NiCr-Mo coating by designing shell-corestructured powders," Acta Materialia, vol. 110, pp. 19-30, 2016.

[15] C. J. Huang, W. Y. Li, Y. Xie, M. P. Plance, H. Liao, and G. Montavon, "Effect of substrate type on deposition behavior and wear performance of $\mathrm{Ni}$-coated graphite/Al composite coatings deposited by cold spraying," Journal of Materials Science \& Technology, vol. 4, no. 33, pp. 338-346, 2017.

[16] S. Sampath, X. Y. Jiang, J. Matejicek, L. Prchlik, A. Kulkarni, and A. Vaidy, "Role of thermal spray processing method on the microstructure, residual stress and properties of coatings: an integrated study for Ni-5 wt.\%Al bond coats," Materials Science and Engineering A, vol. 364, no. 1-2, pp. 216-231, 2004.

[17] R. Troncy, G. Bonnet, and F. Pedraza, "Microstructural characterization of NiAl-Al2O3 composite materials obtained 
by in situ aluminothermic reduction of $\mathrm{NiO}$ for potential coating applications," Materials Chemistry and Physics, vol. 251, no. 1, pp. 123124-123138, 2020.

[18] W. Huang, Z. Tong, Y. Bi et al., "Synthesis and microwave absorption properties of coralloid core-shell structure NiS/ Ni3S4@PPy@MoS2 nanowires," Journal of Colloid and Interface Science, vol. 599, pp. 262-270, 2021.

[19] S. Lokesh, G. Vatsana, K. P. Manoj et al., "Impedance engineered microwave absorption properties of $\mathrm{Fe}-\mathrm{Ni} / \mathrm{C}$ coreshell enabled rubber composites for X-band stealth applications," Journal of Alloys and Compounds, vol. 869, pp. 159360-159370, 2021.

[20] E. V. Makhonina, L. S. Maslennikova, V. V. Volkov et al., "Lirich and Ni-rich transition metal oxides: coating and coreshell structures," Applied Surface Science, vol. 474, no. 30, pp. 25-33, 2019.

[21] X. Wang and Z. Xing, "Preparation and properties of composite nCo) coatings," Coatings, vol. 10, no. 9, pp. 868-879, 2020.

[22] Y. Shuo, C. Jan, C. Y. Chen, J. Richard, D. Garret, and L. Rocco, "Metallurgical bonding between metal matrix and core-shelled reinforcements in cold sprayed composite coating," Scripta Materialia, vol. 177, pp. 49-53, 2020. 